\title{
Synthesis and Optimization of Colloidal Hydroxyapatite Nanoparticles by Hydrothermal Processes
}

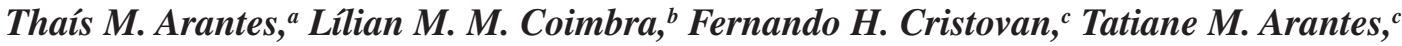 \\ Gabriel M. Rosa ${ }^{a}$ and Luciano M. Lião ${ }^{*, a}$
}

\author{
${ }^{a}$ Instituto de Química, Universidade Federal de Goiás, 74690-900 Goiânia-GO, Brazil \\ ${ }^{b}$ Instituto Federal de Educação, Ciência e Tecnologia Goiano, Avenida Oeste, 350, \\ Parque União, 76200-000 Iporá-GO, Brazil \\ 'Departamento de Química, Universidade Federal de Jataí, Campus Jatobá, \\ BR 364, km 195, No. 3800, 75801-615 Jataí-GO, Brazil
}

\begin{abstract}
This paper reports an optimized, simple, fast and inexpensive method for hydroxyapatite (HA) nanoparticle synthesis. Through a multivariate statistical analysis using a factorial design with $2^{3}$ resolution, an empirical model was developed which allows control of the shape and size of the HA nanoparticles. This model was used to synthesize HA nanoparticles with sizes between 8 and $600 \mathrm{~nm}$, formed by oriented attachment growth mechanism. The structure was confirmed by transmission electron microscopy (TEM) and scanning electron microscopy (SEM) images, which also showed that HA nanoparticles had well-defined nanorod forms and narrow size distributions. It was observed that the model is statistically significant and the main parameter for the growth of crystals in the hydrothermal process was temperature.
\end{abstract}

Keywords: hydroxyapatite, factorial design, hydrothermal, colloids, biomaterials

\section{Introduction}

The application of biomaterials in bone tissue repair has revolutionized orthopedic and dental treatments; the need for further research in the field of implants aiming to discover new applications such as biocompatible materials in many organic systems is evident. To be a viable alternative material to bone, it should be biocompatible, possess a biofunctional resistance and have the necessary mechanical and chemical properties to support the loads imposed. ${ }^{1-3}$ The search for materials with human biocompatibility properties constitutes a major challenge for researchers in the field of new materials. Biomimetism and bioinspiration have been used for the synthesis and development of innovative materials and devices for various biomedical applications. Biomimicry for the synthesis of biomaterials can be performed at distinct levels according to the composition, structure, morphology and physicochemical properties of the synthetic material. ${ }^{4,5}$

Among the biomaterials, hydroxyapatite $\left(\mathrm{Ca}_{10}\left(\mathrm{PO}_{4}\right)_{6}(\mathrm{OH})_{2}, \mathrm{HA}\right)$ has been studied and applied in

*e-mail: lucianoliao@ufg.br several biomedical research fields, due to its similarity with the mineral constituents of human bones and teeth. ${ }^{6}$ Synthetic HA nanoparticles exhibit good biocompatibility, bioactivity and osteoinducibility. ${ }^{1-3,6-8}$ Due to its unique quantum confining effects and the reactivity of the surface area, nanocrystalline HA exhibits better bioactivity, biocompatibility and improved mechanical properties than microcrystalline and bulk HA. ${ }^{9} \mathrm{HA}$ is the major mineral component of bone and teeth structures, corresponding to about $30-70 \%$ of the mass of bones and teeth. ${ }^{3}$ Synthetic HA has been extensively studied and used as it presents biocompatibility with bone minerals and does not present distinct phases of other calcium phosphates $(\mathrm{Ca}-\mathrm{P})$ when carefully synthesized. ${ }^{7,8}$ However, implants made with pure HA exhibit low tensile strength, impact and fatigue resistance. ${ }^{10,11}$ Recent research focuses on overcoming limitations of calcium phosphates and HA ceramics such as low bioresorbability, low surface area and low bioreactivity, and the improvement of their biological properties. ${ }^{4,5}$

The major mineral makeup of bone are homogeneous plate-like HA crystals with lengths of $15-30 \mathrm{~nm}$ and diameters of 30-50 nm, and enamel and dentin are beadshaped HA crystals with diameters of 25-100 nm and lengths 
of $100 \mathrm{~nm}$ to microns. The study of biomineralization and biomimetic assembly involves the search for an advanced method so that the synthesis of HA nanocrystals can be controlled with precision. ${ }^{4,12,13}$ With nanotechnology, it is possible to synthesize inorganic crystals with nanometric dimensions, characterized by high surface area, shape control and structural organization that increases crystalline bioreactivity. For the optimization of the biomedical applications of biomimetic HA, its chemical and physical characteristics such as size, porosity, morphology and surface properties must be adapted according to the application. ${ }^{4}$ Although each of the approaches reported to produce nanometric HA crystals has both scientific and practical relevance, very little attention has been paid to the physical and chemical details involved in controlling the size and shape distribution of particles. Indeed, in the case of particle size distribution, most of the reported synthetic routes produce a mixture of particles with a wide size distribution of tens to hundreds of nanometers, and many do not show shape control. ${ }^{14,15}$

Furthermore, bone is a complex composite of a biopolymer, mostly collagen (type I), and biomineral in a mineralized matrix. ${ }^{13}$ Thus, in this work, the objective was to synthesize homogeneous stable colloidal dispersions of HA nanoparticles with shape and size control to be used as reinforcing agents in biocompatible polymers, which will be used as biomaterials in medical/dental applications.

With respect to synthesis strategies to obtain colloidal nanoparticles of HA, there are various methods such as hydrothermal, ${ }^{16-19}$ chemical precipitate, ${ }^{20,21}$ wet chemical, ${ }^{22,23}$ and sol-gel ${ }^{24}$ methods. Among these, the hydrothermal method has aroused great interest due to its good repeatability, wide temperature range, the possibility to control the form, size, and shape, simplicity of operation, ability to produce crystalline nanoparticles without posterior thermal treatment, ${ }^{25}$ and especially to obtain stable colloidal suspensions of nanoparticles. Another advantage of hydrothermal synthesis is that it does not require the final calcination step to obtain a pure crystalline material. ${ }^{26,27}$ The applications of HA nanoparticles are influenced by the shape, crystallinity and purity of the synthesized material. Therefore, it is important to control the shape, size and crystalline structure of the nanoparticles according to the different synthesis conditions. However, to the best of our knowledge, most studies aiming to obtain HA nanoparticles with varied shapes and sizes use a univariate approach. In this case, all variables are kept at a constant level and only one variable is changed to maximize the property studied. ${ }^{28}$ This process is repeated to evaluate the optimal value for each variable of the system. The univariate method does not consider interactions between variables. Thus, the best value of a variable can lead to an incorrect interpretation of the results. To solve this problem, the multivariate approach should be used, changing all variables at the same time. ${ }^{29,30}$ The multivariable approach is a powerful tool to measure and understand the effects of specific independent variables, as it is possible to estimate interactions between the variables on the experimental response, with a small number of experiments. Furthermore, it allows the prediction of system properties in non-performed experiments.

In this study, low cost and environmentally compatible reagents for the synthesis of pure HA nanoparticles were used. In addition, the synthesized nanoparticles presented high crystallinity, great homogeneity in relation to size and shape without the need for subsequent sizing, and it is still possible to select them. A soft temperature range between $100-140{ }^{\circ} \mathrm{C}$, reaction times of $24-48 \mathrm{~h}$, calcium chloride as calcium source and ammonium hydroxide for $\mathrm{pH}$ control were also applied. In all experiments the $\mathrm{pH}$ was maintained at 9.0. More drastic conditions were employed in Sadat-Shojai et al. ${ }^{19}$ synthesis, such as reaction time of $60 \mathrm{~h}, 200{ }^{\circ} \mathrm{C}$ in the experiment of higher level, $\mathrm{pH}$ variation and additives like urea. In this work an empirical model that allows the control of the shape and size of HA nanoparticles due to the control of the initial experimental conditions was proposed. Although studies using factorial design to understand the effect of some experimental conditions on the final properties of colloidal HA nanoparticles have been previously published, ${ }^{19,21,22,24,25,28,29,31}$ only a few of them evaluated the statistical significance of the effects. Usually, these studies present models that consider the experimental parameters that affect the size of the particles, which were previously identified in univariate studies, but their statistical significance has been ignored, which is not true in multivariate studies. Therefore, this study aims to present an effective way to predict the final particle size of colloidal HA nanoparticles.

\section{Experimental}

HA nanoparticles were synthesized by hydrothermal process. A solution of calcium chloride (Aldrich, 93\%) was added to a $100 \mathrm{~mL}$ autoclave bottle, and added dropwise into an ammonium phosphate (Aldrich, 98\%) aqueous solution. The molar ratio $(\mathrm{Ca} / \mathrm{P})$ was kept constant according to its stoichiometric ratio in HA (1.67). The mixture $\mathrm{pH}$ was adjusted to 9.0 using ammonia aqueous solution (Aldrich, 28-30\%), and heated at different times. After the synthesis time, the reaction system was allowed to cool to room temperature; subsequently, the samples were dried on a Petri dish at $50{ }^{\circ} \mathrm{C}$. The synthesis optimization 
was performed by two-level, three-factor factorial design $\left(2^{3}\right)$, requiring eight experiments to evaluate the parameters influencing the size of HA nanoparticles. The three variables tested were synthesis temperature $(\mathrm{T})$, precursor concentrations $(\mathrm{C})$, and reaction time ( $\mathrm{t}$ ). The experimental conditions used were based on the literature. ${ }^{17-19,25,27,31,32} \mathrm{All}$ matrix calculi were carried out using the free software GUI Octave $^{33}$ (version 3.6), in Microsoft Windows 10 Home 64 bits System.

Two levels, high (+) and low (-), were defined for each factor, as shown in Table 1. The stoichiometric ratio of precursors was kept constant at 1:1, thus, the precursor concentrations used were 0.03 and $0.1 \mathrm{~mol} \mathrm{~L}^{-1}$. Table 1 describes the eight experiments proposed by the fractional factorial design. These experiments were conducted in a random order.

Table 1. Factorial design $2^{3}$ for the HA nanoparticles synthesis

\begin{tabular}{|c|c|c|c|c|c|c|c|c|}
\hline Variable & \multicolumn{4}{|c|}{ Low level (-) } & \multicolumn{4}{|c|}{ High level (+) } \\
\hline Temperature $/{ }^{\circ} \mathrm{C}$ & \multicolumn{4}{|c|}{100} & \multicolumn{4}{|c|}{140} \\
\hline time / $\mathrm{h}$ & \multicolumn{4}{|c|}{24} & \multicolumn{4}{|c|}{48} \\
\hline Concentration / $\left(\mathrm{mol} \mathrm{L}^{-1}\right)$ & \multicolumn{4}{|c|}{0.03} & \multicolumn{4}{|c|}{0.1} \\
\hline \multirow[t]{3}{*}{ Response } & \multicolumn{8}{|c|}{ particle size / nm } \\
\hline & \multicolumn{8}{|c|}{ Experiment No. } \\
\hline & E1 & E2 & E3 & $\mathrm{E} 4$ & E5 & E6 & E7 & E8 \\
\hline Temperature & - & + & - & + & - & + & - & + \\
\hline time & - & - & + & + & - & - & + & + \\
\hline Concentration & - & - & - & - & + & + & + & + \\
\hline
\end{tabular}

Subsequently, the determination of average particle size for each experimental condition, the main effects, and secondary and tertiary effects (interaction effects) were calculated; significant effects were accounted for in the formulation of the model to describe how the factors and interactions can influence the average particle size. The average nanoparticle sizes were obtained using the free software Image $\mathbf{J},{ }^{34}$ counting about 200 particles in several images (about 10 images per sample) obtained in different regions of the sample. In addition, for each sample, synthesis was performed in duplicates that were later characterized by microscopy and used in the construction of histograms.

To identify crystalline structures, the nanoparticles were qualitatively characterized by X-ray diffraction (XRD), using a Rigaku diffractometer model DMax $2500 \mathrm{PC}(\mathrm{CuK} \alpha$ radiation) with $\lambda=1.5406 \AA$, operating in the range of $2 \theta$ from 10 to $110^{\circ}$ with a step of $0.02^{\circ}$ and a step time of $1 \mathrm{~s}$. The Raman spectra were obtained using a Bruker RFS100 spectrometer with neodymium-doped yttrium aluminum garnet (ND-YAG) laser $(1064 \mathrm{~nm})$, using a power of $150 \mathrm{~mW}$, and region of $100-2000 \mathrm{~cm}^{-1}$, with 32 scans and a resolution of $4 \mathrm{~cm}^{-1}$ at room temperature. Qualitative evaluation of the chemical composition was obtained using diffuse reflectance infrared Fourier transform (DRIFT) spectroscopy (Bruker Equinox 55). The spectra were recorded in the range $400-4000 \mathrm{~cm}^{-1}$ at a resolution of $2 \mathrm{~cm}^{-1}$. Transmission electron microscopy (TEM) images were obtained with a JEOL JEM-3010 operating at $300 \mathrm{kV}$ equipped with a GATAN multi-Scan CCD camera model 794. Scanning electron microscopy (SEM) images were recorded with a JEOL JSM-5600LV operated at $20 \mathrm{kV}$, using secondary electrons to form the image. The SEM samples were coated with a thin layer of gold.

\section{Results and Discussion}

HA nanoparticles applications are influenced by morphology and crystallinity. ${ }^{26}$ In that context, it was very important to establish a clear relationship between experimental conditions and particle morphology and crystallinity. The crystalline structures of the samples synthesized with different experimental conditions are shown in Figure 1. All diffraction peaks of the XRD pattern can be easily indexed to a pure hexagonal phase of HA, which agrees with the reported data (Joint Committee on Powder Diffraction Standards (JCPDS) powder diffraction file (PDF) No. 090432). ${ }^{17}$ The results corresponded to a crystalline HA phase with a hexagonal unit cell and lattice parameters $\mathrm{a}=9.432 \AA$ and $\mathrm{c}=6.881 \AA$; no additional peaks were present, especially in the range $27-31^{\circ}$. These peaks can be attributed to tetracalcium phosphate (TTCP) phase or tricalcium phosphate ( $\beta$-TCP) phase which is usually present in the HA nanoparticles. ${ }^{31}$

The crystallite size calculations for the nanoparticles were performed from the Scherrer equation:

$\mathrm{L}=\frac{\mathrm{K} \lambda}{\beta \cos \theta}$

where $\mathrm{L}$ is the crystallite size; $\mathrm{K}$ is the proportionality constant (the Scherrer constant, $K=0.9$ ); $\lambda$ is the wavelength of radiation in the X-rays emission $\mathrm{CuK} \alpha$ $(\lambda=1.5406 \AA)$; $\beta$ is the peak width in full width at half maximum (FWHM); and $\theta$ is Bragg's diffraction angle. ${ }^{35,36}$

Table 2 shows crystallite size (L) for different diffraction peaks in each experiment. Crystallite size for all samples except sample E5 showed relatively close sizes with $\mathrm{L}$ varying from 12 to $23 \mathrm{~nm}$ for most diffraction peaks, only at the peak relative to the plane (002) was 


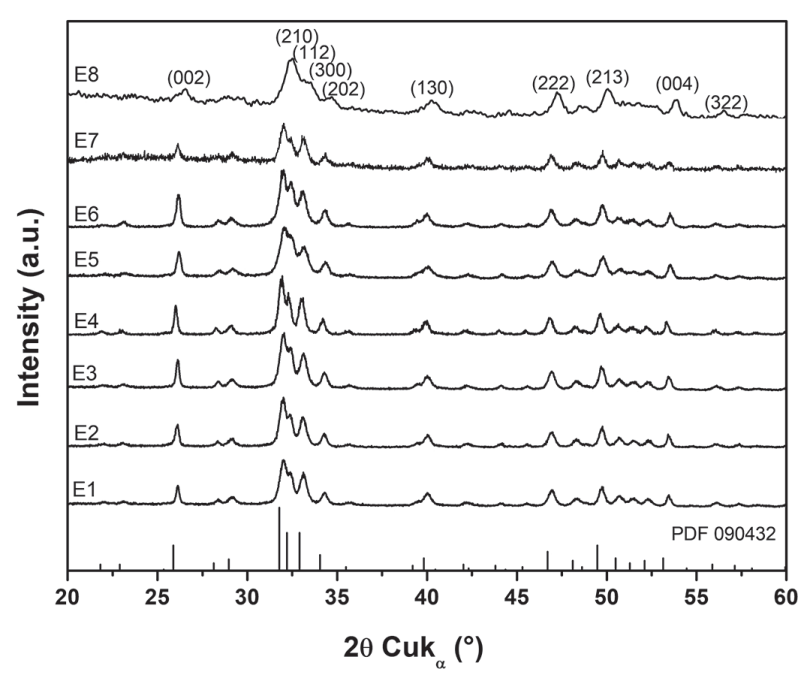

Figure 1. XRD for HA nanoparticles synthesized with different experimental conditions. The individual experimental conditions are shown in Table 1. The Miller index assignment is shown in E8.

observed higher values of $\mathrm{L}$ in the range of $28-48 \mathrm{~nm}$. This result indicates that there is a preferential growth of the nanoparticles perpendicular to this plane. Sample E5 showed $\mathrm{L}$ around $8 \mathrm{~nm}$ for all diffraction peaks indicating that for this synthesis condition the crystallites show no preferential growth in any direction. Dhand et al.$^{23}$ studied the synthesis of nanocrystals of HA by a wet chemistry method and observed this same preferential growth in the (002) direction in the c-axis with crystallite sizes between $15-60 \pm 5 \mathrm{~nm}$, and lengths of approximately $500 \mathrm{~nm}$ confirmed by TEM. ${ }^{23}$ Sadat-Shojai et al.,${ }^{19}$ in hydrothermal synthesis of HA, also observed this same behavior of preferential growth of the nanoparticles and reported that c-axis size increases when the hydrothermal temperature increases, which is accompanied by decrease in growth in the other directions.

Table 2. Crystallite size according to diffraction peaks

\begin{tabular}{lcccccccc}
\hline \multirow{2}{*}{ Plane } & \multicolumn{8}{c}{ Crystallite size (L)/nm } \\
\cline { 2 - 9 } & E1 & E2 & E3 & E4 & E5 & E6 & E7 & E8 \\
\hline$(002)$ & 48 & 34 & 37 & 41 & 9 & 27 & 34 & 28 \\
$(210)$ & 17 & 19 & 17 & 23 & 8 & 19 & 17 & 14 \\
$(112)$ & 17 & 18 & 20 & 22 & 9 & 16 & 21 & 15 \\
$(300)$ & 16 & 16 & 17 & 17 & 8 & 16 & 16 & 13 \\
$(202)$ & 19 & 20 & 23 & 23 & 9 & 20 & 20 & 12 \\
\hline
\end{tabular}

The Raman spectroscopy results for HA nanoparticles are shown in Figure 2. The Raman spectra of all samples are similar and demonstrate typical HA vibrations, with the main lines observed in the spectral range $360-1160 \mathrm{~cm}^{-1}$. The bands at 431 and $450 \mathrm{~cm}^{-1}$ are due to the phosphate $v_{2}$ vibrations, bands at 585 and $610 \mathrm{~cm}^{-1}$ are due to phosphate $v_{4}$ vibrations and the band at $960 \mathrm{~cm}^{-1}$ is due to phosphate $v_{1} \mathrm{PO}_{4}{ }^{3-}$ vibrations in HA phase. ${ }^{17,31}$ The Raman modes observed in the range from $1020-1080 \mathrm{~cm}^{-1}$ can be ascribed to the stretching $v_{1}$ mode of carbonate, ${ }^{17,18,20,21}$ and the bending mode of carbonate at $1045 \mathrm{~cm}^{-1},{ }^{17}$ which overlaps with the wide background of the phosphate $v_{3}$ vibrations. ${ }^{21}$ According to Nosenko et al. ${ }^{31}$ the values of the frequencies of $\mathrm{PO}_{4}{ }^{3-}$ in water obtained from Raman scattering measurements are $v_{1}$ at $936 \mathrm{~cm}^{-1}, v_{2}$ at $415 \mathrm{~cm}^{-1}$, $v_{3}$ at $1010 \mathrm{~cm}^{-1}$, and $v_{4}$ at $558 \mathrm{~cm}^{-1} \cdot{ }^{37}$ Usually, the band at $945 \mathrm{~cm}^{-1}$ is assigned to amorphous calcium phosphate, as can be seen in sample $\mathrm{E} 4,{ }^{38}$ which indicates a highly disordered structure, although not necessarily a completely amorphous one, and $v_{1}$ vibration components of $\mathrm{PO}_{4}{ }^{3-}$ of $\beta$-TCP. ${ }^{30}$ According to the Raman spectra, the formation of amorphous calcium phosphate was verified in condition $\mathrm{E} 4$, probably due to Ostwald ripening particle coarsening process. ${ }^{39,40}$ This process occurs because in experiment E4 the temperature and reaction time were at the highest (+) level and thus the small particles were subjected to redissolution. When they underwent re-nucleation, they initially formed amorphous calcium phosphate, precursor of HA. The same was not observed in experiment E8, where the concentration was also at the highest level, although there were greater availability of ions in the solution. The reaction time in this case was sufficiently large so that all the amorphous phosphate was converted to HA. However, the presence of $\beta$-TCP phase was not observed by XRD. According to Kim et al.,${ }^{41}$ the presence of calcium phosphate phases in HA often exhibits a combination of enhanced bioactivity and mechanical stability that is

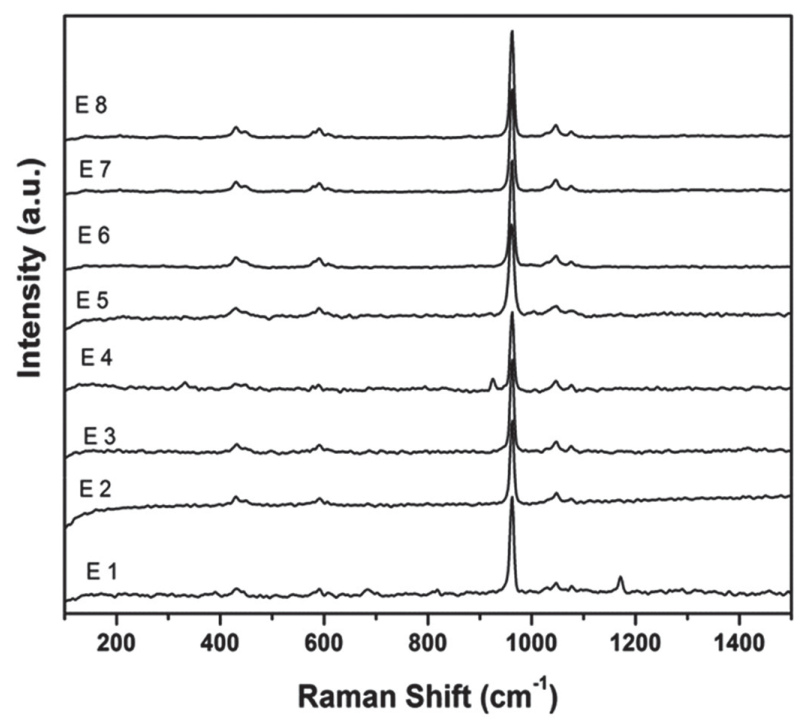

Figure 2. Fourier transform-Raman spectra for HA nanoparticles synthesized according to the factorial design. 
difficult to achieve in single-phase materials. This makes these biphasic bioceramics promising substrate materials for applications in bone tissue regeneration and repair.

Figure 3 presents typical Fourier transform infrared (FTIR) spectra for HA nanoparticles. ${ }^{24,30}$ Stretch bands at 1023 and $1088 \mathrm{~cm}^{-1}$, as well as the deformation bands at 503,561 and $600 \mathrm{~cm}^{-1}$, were observed for the phosphate group $\left(\mathrm{PO}_{4}{ }^{3-}\right){ }^{8,42}$ In addition to the phosphate bands, two bands appeared at 1193 and $868 \mathrm{~cm}^{-1}$, which can be assigned to the $\mathrm{OH}$ in-plane bending and $\mathrm{P}-(\mathrm{OH})$ stretching modes of $\mathrm{HPO}_{4}{ }^{2-}$ groups in the structure, respectively. ${ }^{30}$ The presence of base backbone moieties of phosphate and hydroxyl groups along with calcium confirmed the complete synthesis of HA due to the presence of the band at 632 and $3570 \mathrm{~cm}^{-1} .{ }^{23}$ According to Dhand et al., ${ }^{23}$ peaks around 3570 and $632 \mathrm{~cm}^{-1}$ were characteristic chemical signatures representing the appropriate stoichiometric ratios for the synthesis of HA nanoparticles..$^{23,24,30}$ Additionally, Wang et al..$^{43}$ attributed the narrow band around $3600 \mathrm{~cm}^{-1}$ to $\mathrm{O}-\mathrm{H}$ stretching in the HA crystalline structure.

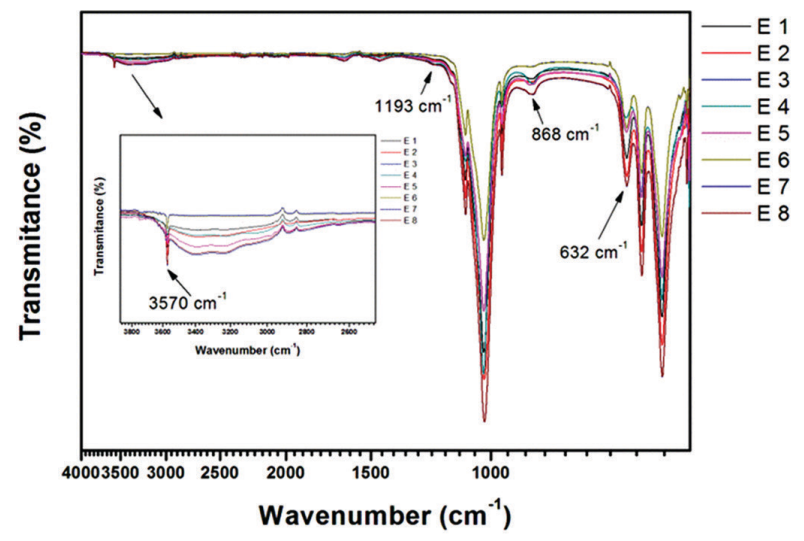

Figure 3. FTIR spectra of HA nanoparticles.

The morphology of all nanoparticle samples is shown in Figure 4. SEM and TEM showed that nanoparticles with rod shapes were obtained for all synthesis conditions. However, at the highest temperature $\left(140{ }^{\circ} \mathrm{C}\right.$, Figure 4 , E8), concentration and time of synthesis, these rods were larger and thinner than those obtained by the other conditions. On the other hand, for sample E5, the TEM image showed rod forms with porous structures due to oriented attachment growth mechanism among the nanoparticles with dimensions of around $8 \mathrm{~nm}$. The other experimental conditions showed nanorod structures; their size distributions are shown in Figure 5 and Table 2. Several authors have also reported the targeted growth of the HA nanoparticles along the c-axis in the direction of the crystallographic plane (002) forming rod-shaped nanoparticles. As observed in the present study, HA nanoparticles also showed growth oriented through the direction-oriented coalescence growth mechanism (002), which can be confirmed both by XRD measurements and by the crystallite size. This coalescence can be clearly verified in the TEM images of the samples of E5, where it is found that the rods are in fact formed by smaller particles which, when joined, grow oriented in a preferred direction. ${ }^{4,23,44}$

From the $2^{3}$ factorial design, eight experiments were performed, making it possible to calculate the main effects and interaction effects (secondary and tertiary effects); these are displayed in Table 3. Figure 6 presents the Pareto plot for the experimental design, which shows that all effects have a positive value, indicating that the particle size increases with the change of the inferior to the superior level of parameters studied and that all effects are significant. In this case, seven effects have $p$-values less than 0.05 , indicating that they are significantly different from zero at the $95.0 \%$ confidence level. The variable that most influenced size was temperature. In experiments 1 and 5, low temperatures and short times were used, and rod-shaped nanoparticles were formed by nanospheres. In experiments using higher temperatures, nucleation in the c-axis was induced, producing nanorods. This was due to the capillary process and the Ostwald ripening process. ${ }^{39}$ Chen et al. ${ }^{45}$ synthesized HA nanoparticles by hydrothermal treatment and observed the self-organization of HA nanorods through the oriented attachment. The nanorods were arranged in order along the c-axis of HA. These formed 3.5 slip-shaped pores between the rods. Using high-resolution transmission electron microscopy (HRTEM), they observed that single crystals of HA may grow in the (002) direction of the HA structure. ${ }^{45}$

Of the eight independent experimental conditions possible for a $2^{3}$ factorial design, seven different effects could be calculated: three individual, three secondary and one tertiary interaction. The effects labeled $\mathrm{E}_{1}, \mathrm{E}_{2}$ and $\mathrm{E}_{3}$ were considered individual effects and stand for the effects respective only to each isolated factor. The effects $E_{12}, E_{13}$ and $E_{23}$ show the combined effect of two factors, and the effect labeled $E_{123}$ denotes the combined effect of the three factors of the factorial design. Only effects with values greater than $5 \%$ were evaluated as significant; therefore, all effects of temperature $\left(E_{1}\right)$, time $\left(E_{2}\right)$ and concentration of salts $\left(\mathrm{E}_{3}\right)$ and the effects arising from the interaction of factors $\left(E_{12}, E_{23}\right.$ and $\left.E_{13}\right)$, as well as the effect labeled $\mathrm{E}_{123}$, could be considered significant effects, and a model accounting for one independent coefficient $\left(b_{0}\right)$ and seven different coefficients $\left(b_{1}, b_{2}, b_{3}, b_{12}, b_{13}, b_{23}, b_{123}\right)$ for each of the effects was proposed (equation 2). Finally, by solving the matrix equation $\mathrm{b}=\left(\mathbf{X}^{\mathbf{t}} \mathbf{X}\right)^{-1} \mathbf{X}^{\mathbf{t}} \mathbf{Y}$, equation 3 was obtained, which describes the model. 

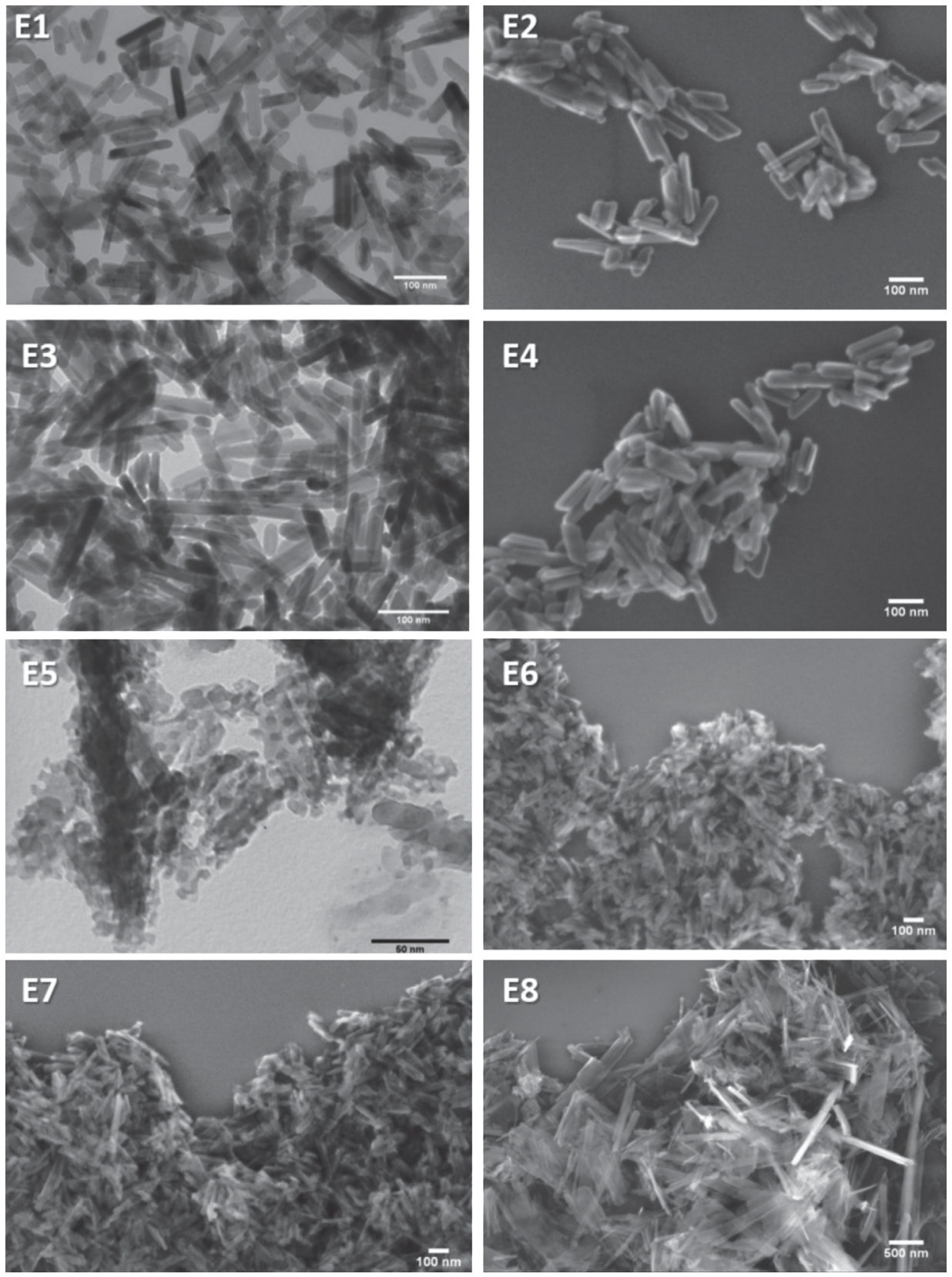

Figure 4. Electron microscopy images of HA nanoparticles synthesized with different experimental conditions, as presented in Table 1: E1 (TEM, scale bar value $100 \mathrm{~nm}$ ); E2 (SEM, scale bar value $100 \mathrm{~nm}$ ); E3 (TEM, scale bar value $100 \mathrm{~nm}$ ); E4 (SEM, scale bar value $100 \mathrm{~nm}$ ); E5 (TEM, scale bar value $50 \mathrm{~nm}$ ); E6 (SEM, scale bar value $100 \mathrm{~nm}$ ); E7 (SEM, scale bar value 100nm); and E8 (SEM, scale bar value $500 \mathrm{~nm}$ ).

$\mathrm{y}=151.08+81.67 \mathrm{~T}+78.67 \mathrm{t}+38.83 \mathrm{C}+57.08 \mathrm{~T} \times \mathrm{t}+$

$60.42 \mathrm{~T} \times \mathrm{C}+75.42 \mathrm{t} \times \mathrm{C}+56.83 \mathrm{~T} \times \mathrm{t} \times \mathrm{C}$

$\mathrm{y}=\mathrm{b} 0+\mathrm{b}_{1} \mathrm{x}_{1}+\mathrm{b}_{2} \mathrm{x}_{2}+\mathrm{b}_{3} \mathrm{x}_{3}+\mathrm{b}_{12} \mathrm{x}_{1} \mathrm{x}_{2}+\mathrm{b}_{13} \mathrm{x}_{1} \mathrm{x}_{3}+\mathrm{b}_{23} \mathrm{x}_{2} \mathrm{x}_{3}+$

$\mathrm{b}_{123} \mathrm{x}_{1} \mathrm{x}_{2} \mathrm{x}_{3}$

In equations 2 and 3 , the $X_{1}$ variable represents the coded value $(-1$ or +1$)$ of the temperature $(T), X_{2}$ represents the coded value of the time $(\mathrm{t})$ and $\mathrm{X}_{3}$ represents the coded value of the precursor concentrations (C) (Table 1). By inserting the coded values of each variable in equation 2 , it was possible to calculate the predicted particle size for each experiment, and consequently, to compare the predicted values with those obtained experimentally; also, the error or residues could be evaluated. The predicted particle size values and the respective residuals, in absolute and percentage values, are displayed in Table 4 , which shows the analysis of variance (ANOVA). The table partitions the variability in particle size into separate pieces for each of the effects. It then tests the statistical significance of each effect by comparing the mean square against an estimate of the experimental error. 

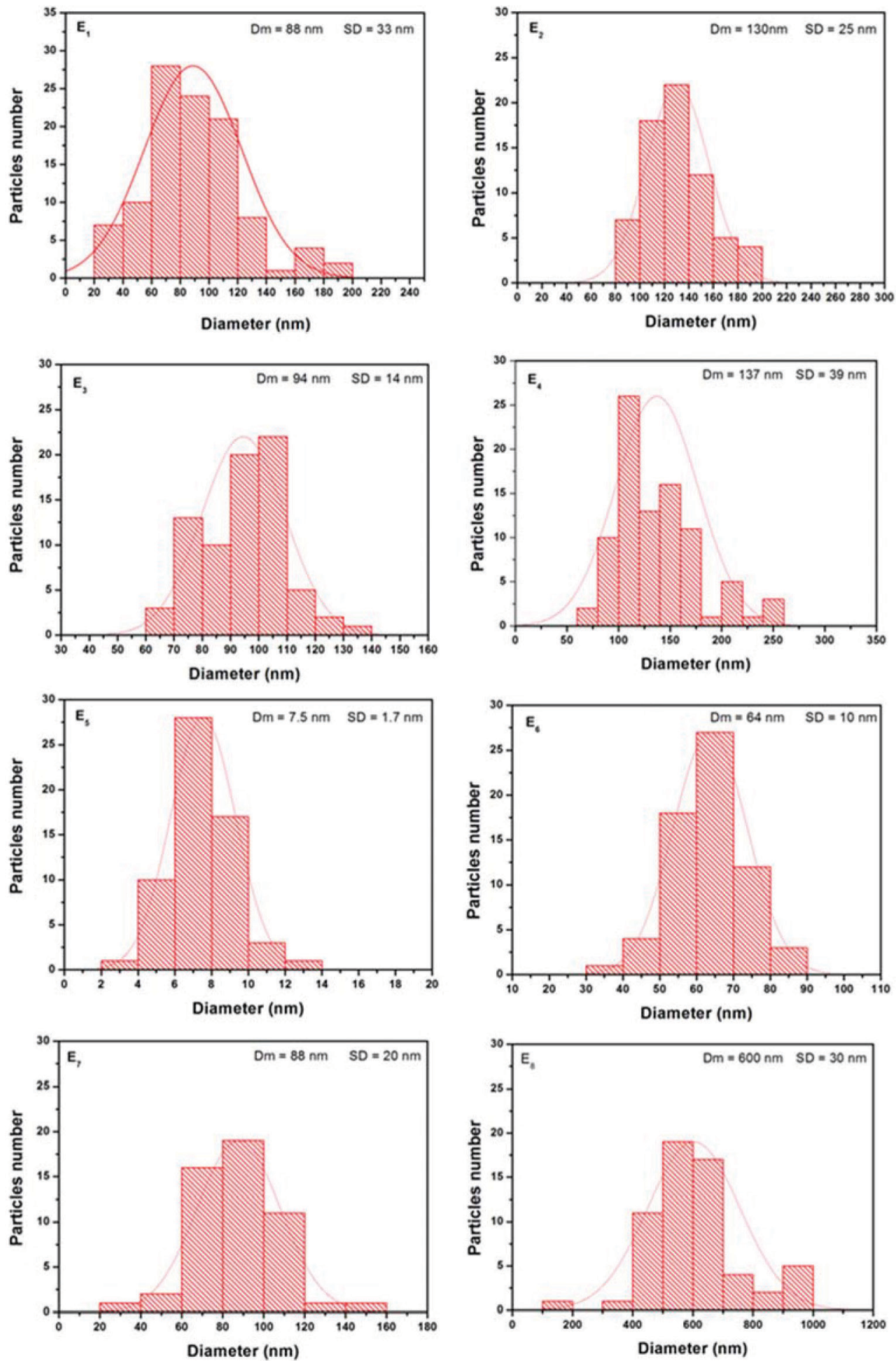

Figure 5. Histograms of size distributions of HA nanoparticles obtained from SEM and TEM images.

The R-squared statistic indicated that the model as fitted explains $95.0121 \%$ of the variability in particle size. The adjusted R-squared statistic, which is more suitable for comparing models with different numbers of independent variables, was $92.8298 \%$. The standard error of the estimate showed that the standard deviation of the residuals was
52.7082. The mean absolute error (MAE) of 22.3729 was the average value of the residuals. The Durbin-Watson (DW) statistic tests the residuals to determine whether there was any significant correlation based on the order in which they occur in the data file. Since the $p$-value was greater than $5.0 \%$, there was no indication of serial autocorrelation 
Table 3. Factorial design matrix and average particle size describing the HA nanoparticle prepared in each experiment. Temperature, time and precursor concentration were the variables studied. The calculated effects for the factorial design are also presented

\begin{tabular}{|c|c|c|c|c|c|c|}
\hline Experiment & $\mathrm{T}$ & $\mathrm{t}$ & $\mathrm{C}$ & \multicolumn{3}{|c|}{ Particle size / nm } \\
\hline 1 & -1 & -1 & -1 & \multicolumn{3}{|c|}{$88 \pm 33$} \\
\hline 2 & +1 & -1 & -1 & \multicolumn{3}{|c|}{$130 \pm 25$} \\
\hline 3 & -1 & +1 & -1 & \multicolumn{3}{|c|}{$94 \pm 14$} \\
\hline 4 & +1 & +1 & -1 & \multicolumn{3}{|c|}{$137 \pm 39$} \\
\hline 5 & -1 & -1 & +1 & \multicolumn{3}{|c|}{$7.5 \pm 1.7$} \\
\hline 6 & +1 & -1 & +1 & \multicolumn{3}{|c|}{$64 \pm 10$} \\
\hline 7 & -1 & +1 & +1 & \multicolumn{3}{|c|}{$88 \pm 20$} \\
\hline 8 & +1 & +1 & +1 & \multicolumn{3}{|c|}{$600 \pm 30$} \\
\hline \multicolumn{7}{|c|}{ Effects } \\
\hline $\mathrm{T}$ & $\mathrm{t}$ & $\mathrm{C}$ & $\mathrm{Tt}$ & $\mathrm{TC}$ & $\mathrm{tC}$ & $\mathrm{TtC}$ \\
\hline 163 & 157 & 77 & 114 & 121 & 151 & 114 \\
\hline
\end{tabular}

T: temperature; t: time; $\mathrm{C}$ : precursor concentration.

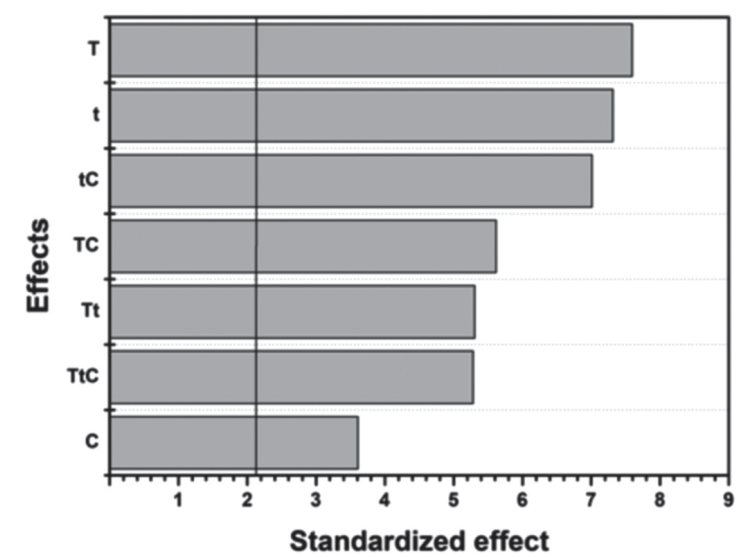

Figure 6. Pareto plot showing the standardized value of mean effect and secondary and tertiary effects.

in the residuals at the 5.0\% significance level. The model was statistically significant. Since the effect due to the precursor concentrations (C) had the lowest standard value, it was possible to yield particles with two different ranges regarding their sizes by fixing $\mathrm{C}$ in either the upper or lower levels. For instance, by fixing the $\mathrm{C}$ factor to +1 $\left(0.10 \mathrm{~mol} \mathrm{~L}^{-1}\right)$, there was a trend to yield bigger particles, whereas smaller particles were expected to be fixed as $\mathrm{C}=-1\left(0.03 \mathrm{~mol} \mathrm{~L}^{-1}\right)$.

Figure 7 a shows that when the $\mathrm{C}$ factor was +1 , the response surface yielded particle sizes ranging from 7.5 to $600 \mathrm{~nm}$. Meanwhile, Figure 7b shows that surface response yielded values ranging from 88 to $137 \mathrm{~nm}$ for $\mathrm{C}=-1$. In summary, Figures $7 \mathrm{a}$ and $7 \mathrm{~b}$ show that within the proposed factorial design and with the model obtained, it was possible to fine-tune the particle size in a range from 7.5 to $600 \mathrm{~nm}$. This represents a great aid for future researches, since many applications of HA nanoparticles are dependent on different particles size.

The results demonstrated that at lower concentrations, the temperature increase was the factor that presented the greatest effect on the model, affecting the size of the nanoparticles; in this case, nanoparticles with a rod format were always obtained. At the higher concentration, both time and temperature influenced the size of the nanoparticles, and resulted in nanoparticles of different shapes. In syntheses using higher reagent concentrations $\left(0.10 \mathrm{~mol} \mathrm{~L}^{-1}\right)$, the increase in times and temperature resulted in a significant increase in the size of the nanoparticles. Additionally, the variation of initial conditions significantly altered the shape of the nanoparticles. Jin et al. ${ }^{25}$ studied the effect of time and temperature modification on the hydrothermal synthesis of HA nanorods in the presence of sodium citrate and observed that with increasing temperature and time, there was an increase in both rod length and width. In addition, in the studied temperature range, they observed that HA nanorods were obtained from primary particles formed in the aqueous phase instead of aggregates or large clusters. Kuśnieruk et al. ${ }^{46}$ studied that HA nanoparticles morphology depended on the executed process parameters in the hydrothermal synthesis. They observed that synthesis temperature increase leads to more regular and spherical HA particles. They have proved that synthesis

Table 4. Corresponding ANOVA table for the proposed model

\begin{tabular}{lccccc}
\hline Source & Sum of squares & Df & Mean square & $F$-Ratio & $p$-Value \\
\hline Temperature (T) & 160148 & 1 & 160148 & 256.60 & 0.0000 \\
time (t) & 148601 & 1 & 148601 & 238.10 & 0.0000 \\
Concentration (C) & 36153 & 1 & 36153 & 57.93 & 0.0001 \\
$\mathrm{Tt}$ & 78147 & 1 & 78147 & 125.21 & 0.0000 \\
$\mathrm{TC}$ & 87664 & 1 & 87664 & 140.46 & 0.0000 \\
$\mathrm{tC}$ & 136580 & 1 & 136580 & 218.84 & 0.0000 \\
TtC & 77463 & 1 & 77463 & 124.12 & 0.0001 \\
Total error & 5696 & 16 & 406.886 & - & - \\
Total & 734744 & 23 & - & - & - \\
\hline
\end{tabular}

Df: degrees of freedom; $F$-ratio: $F$-test at the confidence limit of $95 \%$; $p$-value: $p$-test, significant effects $p<0.05$. 
$0.1 \mathrm{~mol} \mathrm{~L}^{-1}$

(a)

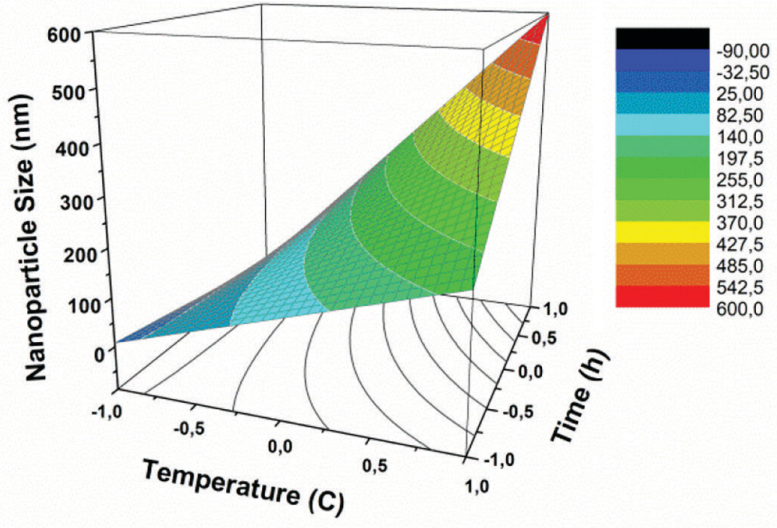

(b)

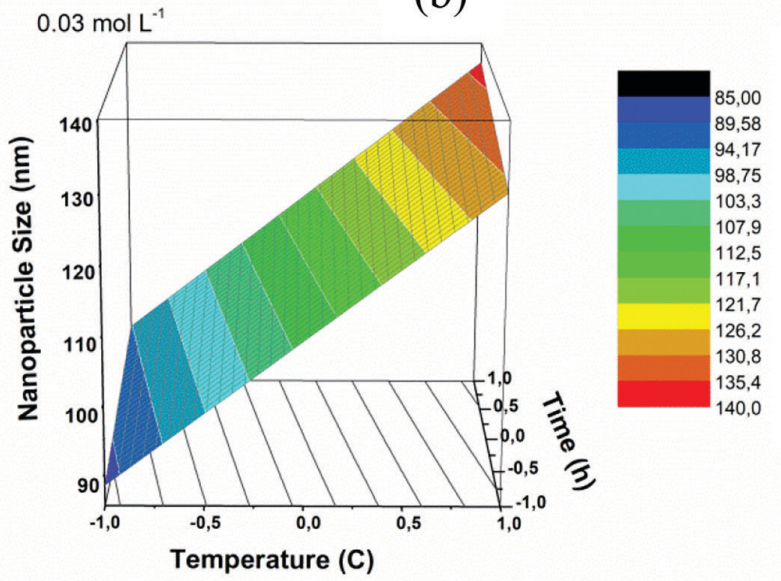

Figure 7. Surface responses of HA nanoparticle size by fixing the salt concentration in the level (a) $+1\left(0.10 \mathrm{~mol} \mathrm{~L}^{-1}\right)$ and (b) $-1\left(0.03 \mathrm{~mol} \mathrm{~L}^{-1}\right)$.

at a low temperature leads to HA crystals with needle morphology, which is confirmed by the SEM and TEM results of type 1 HA nanopowder. Pang et al. ${ }^{40}$ synthesized HA nanoparticles at low temperatures, and obtained particles that were slightly thinner and longer, and more irregular, having less distinct borders. Additionally, these particles tend to form agglomerates. It was also shown that the higher the crystallinity of the powder, the more regular the shape of the particle obtained with ripening time and temperature synthesis increase.

The results show that temperature was the main driving force for crystal growth in the hydrothermal process and is one of the key factors for the preparation of rod-like HA nanoparticles because higher temperatures promote oriented attachement growth. According to SadatShojai et al. ${ }^{19}$ in lower temperatures the counter ions, such as $\mathrm{K}^{+}, \mathrm{SO}_{4}{ }^{2-}$, and $\mathrm{Cl}^{-}$, have a considerable influence on the morphology of the resultant nanoparticles. The use of $\mathrm{SO}_{4}{ }^{2-}$ ions leads to nanoplatelets, possibly due to the strong interaction between $\mathrm{Ca}^{2+}$ and $\mathrm{SO}_{4}{ }^{2-}$ ions, while
$\mathrm{K}^{+}$ions hindered the growth of nanocrystals due to the interaction between $\mathrm{K}^{+}$and $\mathrm{OH}^{-}$or $\mathrm{PO}_{4}{ }^{3-}$ ions. $\mathrm{Cl}^{-}$ions could help to form nanorods, possibly due to the increase in solution polarity. This study demonstrated that the HA nanoparticles with modified shape could be prepared by using the combined effects of temperature and counter ions, which are simple, inexpensive and eco-friendly. ${ }^{23,26}$

\section{Conclusions}

HA nanoparticles were successfully synthesized by hydrothermal method using friendly synthesis conditions. Due the conditions and experiments studied, homogeneous colloidal nanoparticles were obtained in their form and crystallinity, having a selective chemical composition, being this a reproducible and simpler method. Synthesis optimization was performed using factorial design where it was possible to control shape and size of the nanoparticles. Through this approach it was possible to construct an empirical mathematical model, which enabled to develop a surface response plot to screen the synthetic system. The characterization using XRD showed that HA nanoparticle is composed of pure hexagonal phase that confirms the homogeneity of the synthesized materials. The structure was corroborated by TEM and SEM images, which also showed that HA nanoparticles had well-defined nanorod forms and narrow size distributions with sizes between 8 and $600 \mathrm{~nm}$, formed by oriented attachment growth mechanism. Raman spectra analyses showed that the presence of $\beta$-TCP phase in HA nanoparticles can improve the mechanical stability and bioactivity. The HA nanoparticles morphological analysis demonstrated that these properties are affected by synthesis conditions and the main parameter for the growth of crystals in the hydrothermal process was temperature. These results demonstrate the possibility of maximizing the synthesis control of the HA nanoparticles by using a factorial design, a simple but not simplistic methodology.

\section{Acknowledgments}

We would like to thank Universidade Federal de Goiás and Instituto Federal Goiano for structural support as well as FINEP, FAPEG, CNPq and CAPES for continued financial support and scholarships.

\section{References}

1. Feng, Q. L.; Cui, F. Z.; Wang, H.; Kim, T. N.; Kim, J. O.; J. Cryst. Growth 2000, 210, 735.

2. Storz, O.; Gasthuber, H.; Woydt, M.; Surf. Coat. Technol. 2001, $76,140$. 
3. Almeida Filho, E.; Assis, C. M.; Vercik, L. O.; Guastaldi, A. C.; Quim. Nova 2007, 30, 1229.

4. Roveri, N.; Iafisco, M.; Nanotechnol., Sci. Appl. 2010, 3, 107.

5. Wang, H.; Li, Y.; Zuo, Y.; Li, J.; Ma, S.; Cheng, L.; Biomaterials 2007, 28, 3338.

6. Shin, H.; Jo, S.; Mikos, A. G.; Biomaterials 2003, 24, 4353.

7. Valima, T.; Laaksovirta, S.; Biomaterials 2004, 25, 1225.

8. Cangemi, J. M.; Santos, A. M.; Claro Neto, S. E.; Chierice, G. O.; Polim.: Cienc. Tecnol. 2008, 18, 201.

9. Varadarajan, N.; Balu, R.; Rana, D.; Ramalingam, M.; Sampath Kumar, T. S.; J. Biomater. Tissue Eng. 2014, 4, 295.

10. Guastaldi, A. C.; Metal. Mater. 2003, 59, 442.

11. Choi, D.; Marra, K. G; Kumta, P. N.; Mater. Res. Bull. 2004, 39, 417.

12. Tampieri, A.; Celotti, G.; Landi, E.; Anal. Bioanal. Chem. 2005, 381, 568.

13. Cai, Y.; Tang, R.; J. Mater. Chem. 2008, 18, 3775.

14. Roveri, N.; Palazzo, B.; Iafisco, M.; Expert Opin. Drug Delivery 2008, 5, 861 .

15. Leena, M.; Rana, D.; Webster, T. J.; Ramalingam, M.; Mater. Chem. Phys. 2016, 180, 166.

16. Murakami, S.; Kato, K.; Enari, Y.; Kamitakahara, M.; Watanabe, N.; Ioku, K.; Ceram. Int. 2012, 38, 1649.

17. Jin, X.; Zhuang, J.; Zhang, Z.; Guo, H.; Tan, J.; J. Colloid Interface Sci. 2015, 443, 125.

18. Zhao, X. Y.; Zhu, Y. J.; Lu, B. Q.; Chen, F.; Qi, C.; Zhao, J.; Wu, J.; Mater. Res. Bull. 2014, 55, 67.

19. Sadat-Shojai, M.; Atai, M.; Nodehi, A.; J. Braz. Chem. Soc. 2011, 22, 571 .

20. Chen, Z.; Fu, Y.; Cai, Y.; Yao, J.; Mater. Lett. 2012, 68, 361.

21. Gao, S.; Sun, K.; Li, A.; Wang, H.; Mater. Res. Bull. 2013, 48, 1003.

22. Okada, M.; Furuzono, T.; J. Colloid Interface Sci. 2011, 360, 457.

23. Dhand, V.; Rhee, K. Y.; Park, S.-J.; Mater. Sci. Eng., C 2014, 36, 152.

24. Bakan, F.; Laçin, O.; Sarac, H.; Powder Technol. 2013, 233, 295.

25. Jin, X.; Chen, X.; Cheng, Y.; Wang, L.; Hu, B.; Tan, J.; J. Colloid Interface Sci. 2015, 450, 151.

26. Wang, L.; Weng, L.; Wang, L.; Song, S.; J. Ceram. Soc. Jpn. 2010, 118, 1195.
27. Wijesinghe, W. P. S. L.; Mantilaka, M. M. M. G. P. G.; Premalal, E. V. A.; Herath, H. M. T. U.; Mahalingam, S.; Edirisinghe, M.; Rajapakse, R. P. V. J.; Rajapakse, R. M. G.; Mater. Sci. Eng., C 2014, 42, 83 .

28. Arantes, T. M.; Pinto, A. H.; Leite, E. R.; Longo, E.; Camargo, E. R.; Colloids Surf., A 2012, 415, 209.

29. Massart, D. L.; Vandeginste, B. G. M.; Deming, S. N.; Michotte, Y.; Kaufman, L.; Chemometrics: A Textbook; Elsevier: Amsterdam, 1988.

30. Jillavenkatesa, A; Condrate, R. A.; Spectrosc. Lett. 1997, 30, 1561.

31. Nosenko, N. V.; Strutynska, N.; Vorona, I.; Zatovsky, I.; Dzhagan, V.; Lemishko, S.; Epple, M.; Prymak, O.; Baran, N.; Ishchenko, S.; Slobodyanik, N.; Prylutskyy, Y.; Klyui, N.; Temchenko, V.; Nanoscale Res. Lett. 2015, 10, 464.

32. Bhattacharjee, P.; Naskar, D.; Maiti, T. K.; Bhattacharya, D.; Kundu, S. C.; J. Colloid Interface Sci. 2016, 472, 16.

33. GUI Octave, version 3.6, GNU, United States, 2017.

34. Image J, version 1.5.1, NIH, United States, 2017.

35. Scherrer, P.; Nachr. Ges. Wiss. Göttingen, Math.-Phys. Kl. 1918, $26,98$.

36. Langford, J. I.; Wilson, A. J. C.; J. Appl. Crystallogr. 1978, 11, 102.

37. Rudolph, W. W.; Irmer, G.; Appl. Spectrosc. 2007, 61, 1312.

38. Sauer, G. R.; Zunic, W. B.; Durig, J. R.; Wuthier, R. E.; Calcif. Tissue Int. 1994, 54, 414.

39. Manoj, M.; Subbiah, R.; Mangalaraj, D.; Ponpadian, N.; Viswanathan, C.; Park, K.; Nanobiomedicine 2015, 2, 1.

40. Pang, Y. X.; Bao, X.; J. Eur. Ceram. Soc. 2003, 23, 1697.

41. Kim, H.; Camata, R. P.; Vohra, Y. K.; Lacefield, W. R.; J. Mater. Sci.: Mater. Med. 2005, 16, 961.

42. El-Bahy, G. S.; J. Appl. Polym. Sci. 2011, 122, 3270.

43. Wang, M.; Qian, R.; Bao, M.; Gu, C.; Zhu, P.; Mater. Lett. 2018 , $210,203$.

44. Jokić, B.; Mitrić, M.; Radmilović, V.; Drmanić, S.; Petrović, R.; Janaćković, D.; Ceram. Int. 2011, 37, 167.

45. Chen, J. D.; Wang, Y. J.; Wei, K.; Zhang, S. H.; Shi, X. T.; Biomaterials 2007, 28, 2275.

46. Kuśnieruk, S.; Wojnarowicz, J.; Chodara, A.; Chudoba, T.; Gierlotka, S.; Lojkowski, W.; Beilstein J. Nanotechnol. 2016, 7, 1586 . 